\title{
Induction of Sustained Clinical Remission in Early Axial Spondyloarthritis Following Certolizumab Pegol Treatment: 48-Week Outcomes from C-OPTIMISE
}

\author{
Robert Landewé $\cdot$ Désirée van der Heijde $\cdot$ Maxime Dougados • \\ Xenofon Baraliakos · Filip Van den Bosch · Karl Gaffney • \\ Lars Bauer - Bengt Hoepken · Natasha de Peyrecave $\cdot$ Karen Thomas · \\ Lianne S. Gensler
}

Received: April 17, 2020 / Published online: June 11, 2020

(C) The Author(s) 2020

\section{ABSTRACT}

Introduction: Achievement of remission is a key treatment goal for patients with axial spondyloarthritis (axSpA). C-OPTIMISE assessed achievement of sustained clinical remission in patients with axSpA, including radiographic

Digital Features To view digital features for this article go to: https://doi.org/10.6084/m9.figshare.12357767.

Electronic Supplementary Material The online version of this article (https://doi.org/10.1007/s40744020-00214-7) contains supplementary material, which is available to authorized users.

R. Landewé $(\square)$

Amsterdam Rheumatology and Clinical

Immunology Center, Amsterdam, The Netherlands

e-mail: landewe@rlandewe.nl

R. Landewé

Zuyderland Medical Center, Heerlen, The

Netherlands

D. van der Heijde

Department of Rheumatology, Leiden University

Medical Center, Leiden, The Netherlands

M. Dougados

Department of Rheumatology, Hôpital Cochin, Assistance Publique-Hôpitaux de Paris, Université de Paris, Paris, France

M. Dougados

INSERM (U1153): Clinical Epidemiology and Biostatistics, PRES Sorbonne Paris-Cité, Paris, France (r) and non-radiographic (nr) axSpA, during certolizumab pegol (CZP) treatment, and subsequent maintenance of remission following CZP dose continuation, dose reduction or withdrawal. Here, we report outcomes from the first 48 weeks (induction period) of C-OPTIMISE, during which patients received open-label CZP.

Methods: C-OPTIMISE (NCT02505542) was a two-part, multicenter, phase $3 \mathrm{~b}$ study in adult patients with early axSpA (r-/nr-axSpA), including a 48-week open-label induction period followed by a 48-week maintenance period. Patients with active adult-onset

X. Baraliakos

Ruhr-University Bochum, Herne, Germany

F. Van den Bosch

Department of Internal Medicine and Pediatrics, VIB Center for Inflammation Research, Ghent University, Ghent, Belgium

K. Gaffney

Rheumatology Department, Norfolk and Norwich University Hospital NHS Foundation Trust,

Norwich, UK

L. Bauer $\cdot$ B. Hoepken $\cdot$ K. Thomas

UCB Pharma, Monheim am Rhein, Germany

N. de Peyrecave

UCB Pharma, Brussels, Belgium

L. S. Gensler

University of California San Francisco, San

Francisco, CA, USA 
axSpA, $<5$ years' symptom duration, and fulfilling Assessment of SpondyloArthritis international Society classification criteria, were included. During the induction period, patients received a loading dose of CZP $400 \mathrm{mg}$ at weeks 0,2 , and 4 , followed by CZP $200 \mathrm{mg}$ every 2 weeks $(\mathrm{Q} 2 \mathrm{~W})$ up to week 48 . The main outcome of the 48-week induction period was the achievement of sustained clinical remission (defined as an Ankylosing Spondylitis Disease Activity Score [ASDAS] $<1.3$ at week 32 and $<2.1$ at week 36 [or vice versa], and $<1.3$ at week 48).

Results: In total, 736 patients (407 with r-axSpA, 329 with nr-axSpA) were enrolled into the study. At week 48, 43.9\% (323/736) of patients achieved sustained remission, including $42.8 \%(174 / 407)$ of patients with r-axSpA and $45.3 \%(149 / 329)$ with nr-axSpA. Patients also demonstrated substantial improvements in axSpA symptoms, MRI outcomes and quality of life measures. Adverse events occurred in $67.9 \%$ (500/736) of patients, of which $6.0 \%(44 / 736)$ were serious.

Conclusions: Over $40 \%$ of patients with early axSpA achieved sustained remission during 48 weeks of open-label CZP treatment. Additionally, patients across the axSpA spectrum demonstrated substantial improvements in imaging outcomes and quality of life following treatment. No new safety signals were identified.

Trial Registration: NCT02505542.

Keywords: Axial spondyloarthritis; Clinical remission; Early disease; TNF inhibitor

\section{Key Summary Points}

\section{Why carry out this study?}

Achievement of remission is a key treatment goal for patients with axial spondyloarthritis (axSpA), a chronic inflammatory disease characterized by chronic lower back pain and stiffness with a subsequent loss of function that imposes a substantial burden on patients' quality of life.
The induction period of C-OPTIMISE assessed achievement of sustained clinical remission in patients with early active axSpA, including radiographic and nonradiographic axSpA, during open-label treatment with the TNF inhibitor certolizumab pegol (CZP).

\section{What was learned from the study?}

After 48 weeks of CZP treatment, 43.9\% (323/736) of patients achieved sustained remission, including $42.8 \%$ (174/407) of patients with radiographic axSpA and $45.3 \%(149 / 329)$ with non-radiographic axSpA. There were also substantial improvements in axSpA signs and symptoms, physical function, quality of life, and MRI outcomes.

These results confirm that CZP is a suitable treatment option for patients across the broad axSpA spectrum, and provide further support for the concept of axSpA as a single disease, encompassing both radiographic and non-radiographic axSpA.

\section{INTRODUCTION}

Axial spondyloarthritis (axSpA) is a chronic inflammatory disease that affects the axial skeleton and is characterized by chronic lower back pain. Peripheral manifestations include arthritis, enthesitis, and dactylitis, while extramusculoskeletal manifestations of the disease extend to acute anterior uveitis, psoriasis, and inflammatory bowel disease, amongst others $[1,2]$. The two sub-types of axSpA, radiographic axSpA (r-axSpA; also known as ankylosing spondylitis) and non-radiographic axSpA (nraxSpA), are differentiated by the degree of structural damage of the sacroiliac joints observed using pelvic radiography (as part of the modified New York classification criteria) [2-4]. Despite this difference, the burden of disease for patients in terms of clinical presentation, quality of life, and extra-musculoskeletal 
manifestations is comparable between $\mathrm{r}$-axSpA and nr-axSpA $[5,6]$.

Symptom onset in axSpA often occurs in the second to fourth decade of a patient's life, necessitating early and effective treatment to limit the impact of the disease on physical function, work and social productivity, and overall quality of life [7]. In addition to this, diagnosis is typically delayed for several years after the onset of symptoms, although the extent of this delay shows geographic variation [8-12]. Efforts to reduce the diagnostic delay have had limited success, with recent studies still reporting delays of up to 14 years in some regions $[10,12]$.

Current treatment options for patients with axSpA include non-steroidal anti-inflammatory drugs (NSAIDs) in combination with physical exercise and physical therapy as a first-line treatment, followed by tumor necrosis factor inhibitors (TNFi) and interleukin (IL)-17A inhibitors as second-line treatments [13]. Clinical remission is now recommended as a major treatment target in the Assessment of SpondyloArthritis international Society (ASAS)/European League Against Rheumatism (EULAR) recommendations for axSpA and treat-to-target recommendations for spondyloarthritis [14]. Once remission has been achieved, strategies for the maintenance of remission are necessary to prevent future deterioration in disease status. Given the high cost of TNFi and patients wanting to limit their long-term exposure to biologic therapy, dose reduction and treatment withdrawal of TNFi have been explored as options for maintaining remission [15-17]. However, results from previous studies suggest that complete treatment withdrawal in axSpA often leads to relapse $[18,19]$. In addition, there are few controlled studies evaluating the maintenance of remission following dose reduction and/or withdrawal, and none that evaluate this in both the r- and nr-axSpA subpopulations.

The PEGylated, Fc-free TNFi certolizumab pegol (CZP) is an effective and well-tolerated treatment for patients with axSpA, and is approved for the treatment of both $\mathrm{r}-\mathrm{axSpA}$ and nr-axSpA [14, 20, 21]. The phase 3b C-OPTIMISE trial investigated the use of CZP for the induction and maintenance of remission in patients with early axSpA, including those with r-axSpA and nr-axSpA. Here we report outcomes from the first 48 weeks of C-OPTIMISE, during which patients were treated with open-label CZP to induce sustained remission. Results from the maintenance period of C-OPTIMISE are reported elsewhere [22].

\section{METHODS}

\section{Study Design}

C-OPTIMISE (ClinicalTrials.gov number NCT02505542) was a two-part, multicenter phase $3 b$ study in adult patients with axSpA (including r-axSpA and nr-axSpA) comprising a 48-week open-label induction period, followed by a 48-week maintenance period [22]. The study aimed to evaluate the induction of sustained remission and the effect of CZP maintenance dose continuation, reduction, or withdrawal on flares in patients who had achieved sustained remission (Fig. 1a).

During the induction period (baseline to week 48), patients received a loading dose of CZP $400 \mathrm{mg}$ at weeks 0,2 and 4, followed by open-label CZP $200 \mathrm{mg}$ every 2 weeks (Q2W) until week 48. Patients achieving sustained remission during this 48-week induction period were eligible to proceed to the maintenance phase of the C-OPTIMISE study. Sustained remission was recorded as achieved when a subject had an Ankylosing Spondylitis Disease Activity Score (ASDAS) [23, 24] $<1.3$ at week 32 or 36 (if ASDAS was $<1.3$ at week 32 , it must have been $<2.1$ at week 36 , or vice versa) and at week 48.

The maintenance period (weeks 48-96) was a randomized, double-blind period which investigated the efficacy and safety of CZP treatment in patients who had achieved sustained remission during the induction period. These patients were randomized to CZP $200 \mathrm{mg}$ Q2W (full maintenance dose), CZP $200 \mathrm{mg}$ Q4W (reduced maintenance dose) or placebo (withdrawal) [22].

The C-OPTIMISE study was approved by institutional review boards and independent ethics committees at participating sites 
A

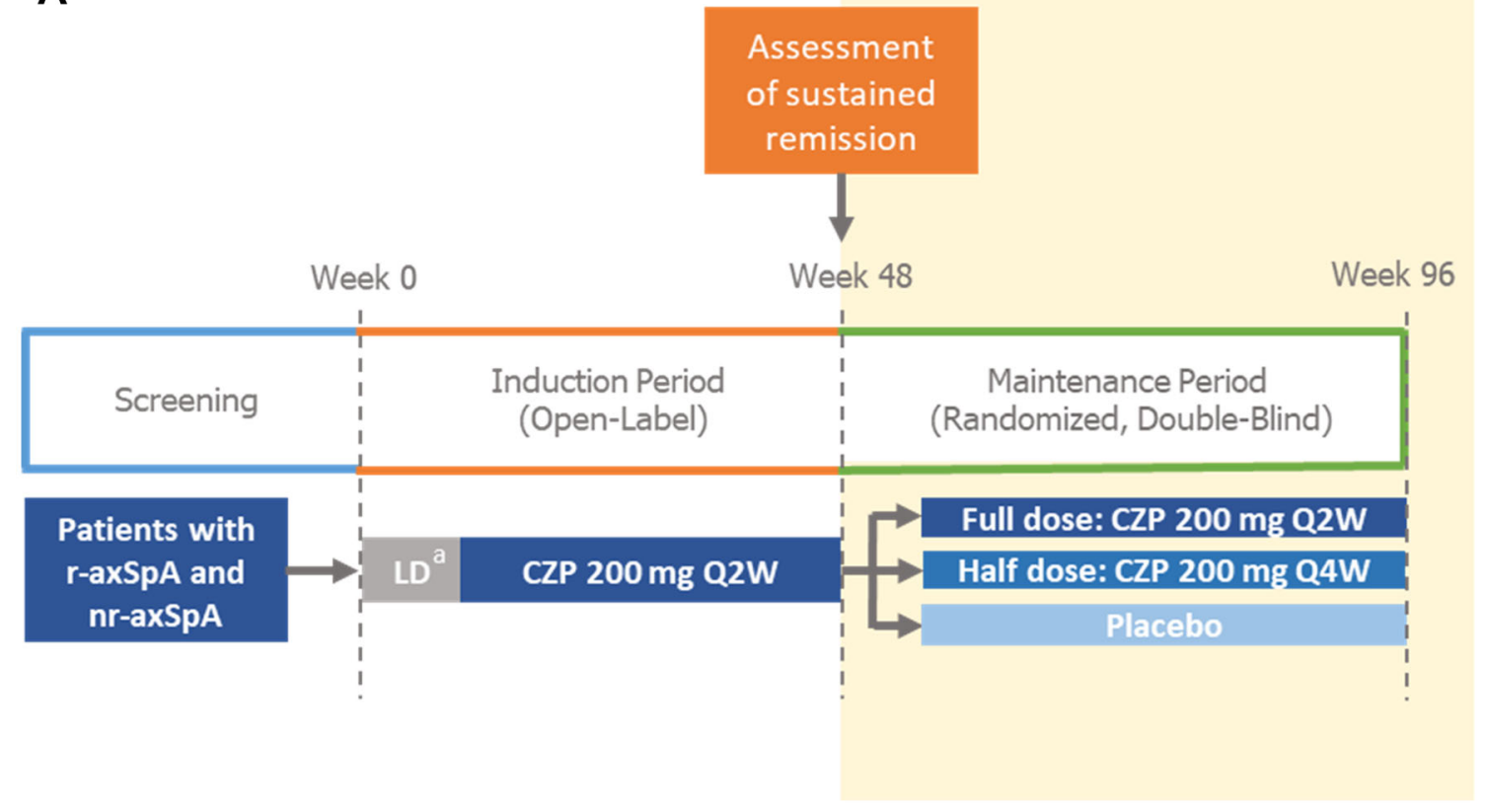

B

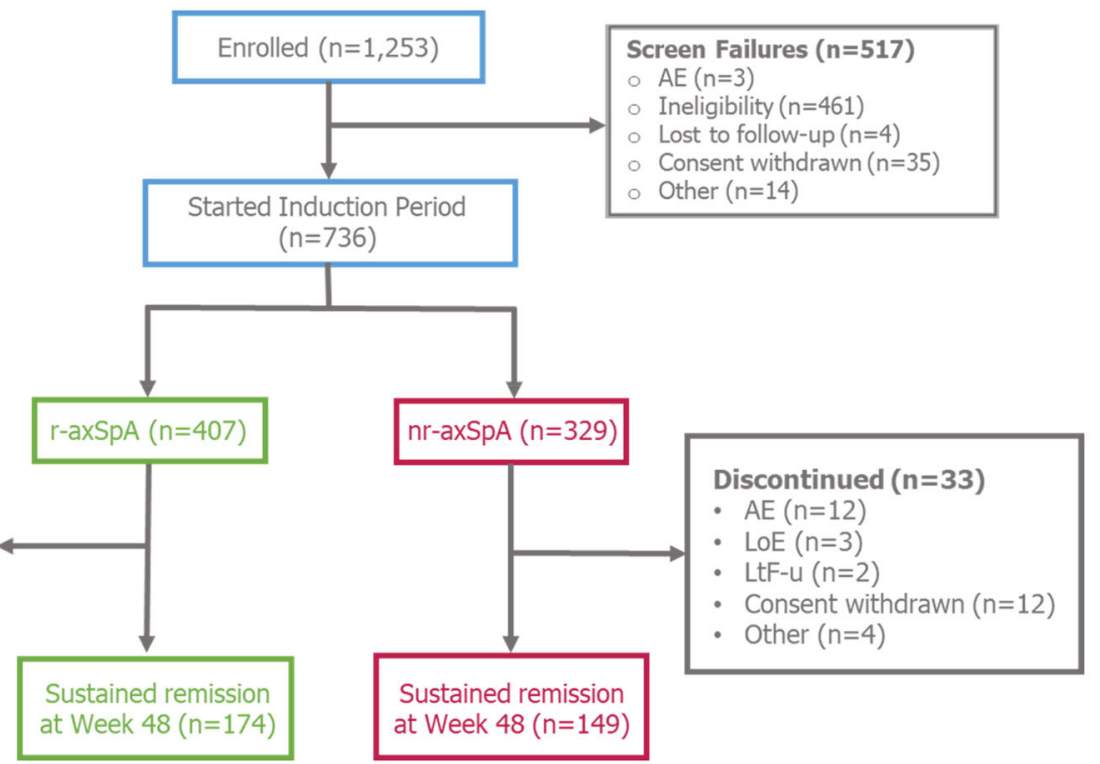

Fig. 1 C-OPTIMISE study design (a) and patient disposition (b). ${ }^{\text {a }}$ The LD consisted of CZP $400 \mathrm{mg}$ at weeks 0, 2 and 4. $L D$ loading dose, $r$-axSpA radiographic axial spondyloarthritis, $n r-a x S p A$ non-radiographic axial

spondyloarthritis, $C Z P$ certolizumab pegol, $Q 2 W$ every 2 weeks, $Q 4 W$ every 4 weeks, $A E$ adverse event, $L o E$ lack of efficacy, $L t F-u$ lost to follow-up 
(Supplementary Material) and was conducted in accordance with local regulations and the International Conference on Harmonization Good Clinical Practice requirements, based on the Declaration of Helsinki. All patients provided informed consent to participate.

\section{Patients}

Eligible patients were between the ages of 18 and 45 years, and had a documented diagnosis of adult-onset axSpA which met ASAS classification criteria [25], a symptom duration of $\geq 3$ months but $<5$ years, and active disease (defined as ASDAS $\geq 2.1$, Bath Ankylosing Spondylitis Disease Activity Index [BASDAI] $\geq 4$, and spinal pain $\geq 4$ on a $0-10$ numerical rating scale [BASDAI item 2]). In addition, all patients must have had inadequate response, contraindication, or intolerance to $\geq 2$ NSAIDs.

Both subpopulations of axSpA (r-axSpA and $n r-a x S p A)$ were included in the study. Central reading by two independent readers (plus adjudicator, if necessary) was applied to all radiographs. Patients fulfilling the ASAS classification criteria and the imaging criterion of the modified New York classification criteria [26] were classified as having r-axSpA. Those fulfilling the ASAS classification criteria but not the modified New York classification criteria, and with objective signs of inflammation (C-reactive protein level above the upper limit of normal [10 mg/l], and/or evidence of active sacroiliitis on magnetic resonance imaging) were classified as having nr-axSpA.

\section{Study Procedures}

Patients visited their respective study sites for administration of study drug and study assessments at weeks $0,2,4,12,24,32,36$, and week 48 , plus an additional visit $3-5$ days prior to the week 48 visit. Patients were taught to self-administer their study medication at weeks 2 and 4 , and then self-administered at each of the remaining time points.

\section{Outcomes}

The primary outcome of C-OPTIMISE was the proportion of patients not experiencing a flare (ASDAS $\geq 2.1$ [high disease activity] at two consecutive visits or ASDAS $>3.5$ [very high disease activity] at any visit) during the maintenance period (weeks 48-96). These outcomes are reported elsewhere [22].

The main secondary outcome (reported herein) was the percentage of patients achieving sustained remission at week 48 , the end of the open-label induction phase. Additional secondary outcomes included assessment of ASDAS status (ASDAS inactive disease [ID], low disease [LD] activity, high disease activity and very high disease activity) [18] and change from baseline in ASDAS major improvement (MI; ASDAS reduction from baseline of $\geq 2$ ) and clinically important improvement (CII; ASDAS reduction from baseline of $\geq 1.1$ ) [18].

Other outcomes included change from baseline in ASAS response rates (ASAS20, ASAS40 and ASAS5/6), ASAS partial remission (PR) $[19,20]$, BASDAI50, mean ASDAS, BASDAI [21], Bath Ankylosing Spondylitis Functional Index (BASFI) [22] and Bath Ankylosing Spondylitis Metrology Index (BASMI; linear definition) [23, 24], Ankylosing Spondylitis Quality of Life (ASQoL) and 36-Item Short Form Survey (SF-36) [27, 28], and MRI outcomes, including sacroiliac joint Spondyloarthritis Research Consortium of Canada (SIJ SPARCC) score [29] and the Berlin modification of the Ankylosing Spondylitis spine MRI score for activity (ASspiMRI-a) [22]. Mean Maastricht Ankylosing Spondylitis Enthesitis Score (MASES) and tender and swollen joint counts (44 joints evaluation) were also evaluated at week 48.

\section{Safety Data}

Safety analyses included all patients who received $\geq 1$ dose of study medication during the induction period. Treatment-emergent adverse events (TEAEs) are reported as the number of patients experiencing each event and were classified according to the Medical 
Dictionary for Regulatory Activities (MedDRA) version 19.0. Serious TEAEs were defined as medical occurrences that were life-threatening or led to death, hospitalization, congenital anomalies or birth defects, persistent or significant disability, or were considered medically important by the study investigator (regardless of severity). Event rates (ER) per 100 patientyears (PY) were calculated for all TEAEs and serious TEAEs (to include repeat events in the same patients).

\section{Statistical Analysis}

It was assumed that approximately $28 \%$ of patients would achieve sustained remission at the end of the open-label induction period. Hence, 750 patients were planned for enrolment into the study in order to provide sufficient power to detect differences (at a two-sided significance level of 0.05) between the CZP $200 \mathrm{mg}$ Q2W and CZP 200 Q4W treatment groups vs. placebo during the 48 -week maintenance period of the study.

The percentage of patients achieving sustained remission is summarized using descriptive statistics (counts and percentages). Continuous data are summarized using mean and standard deviation (SD). Missing data for secondary outcomes were imputed using nonresponder imputation (NRI) for binary response measures, and last observation carried forward (LOCF) for continuous measures. For additional outcomes (not primary or secondary), observed data are reported.

Statistical analyses were performed using SAS Version 9.3.

\section{RESULTS}

\section{Patient Disposition and Baseline Characteristics}

Out of 1253 screened patients, 736 were enrolled in the open-label induction period, including 407 patients with r-axSpA and 329 patients with nr-axSpA (Fig. 1b). The majority of screen failures $(n=461)$ were due to patients not meeting study eligibility criteria. Baseline characteristics were generally comparable for patients with r-axSpA and nr-axSpA (Table 1). However, as expected, a higher proportion of patients with r-axSpA were male (78.4\%) compared to nr-axSpA (59.3\%). Patients with r-axSpA also had a longer average symptom duration at baseline than those with nr-axSpA (3.7 vs. 2.9 years).

Overall, $89.5 \%$ (659/736) axSpA patients completed the open-label induction period, including $89.2 \%(363 / 407)$ patients with r-axSpA and 90.0\% (296/329) patients with nraxSpA.

Of the 77 patients who discontinued during the induction period after starting open-label treatment, reasons for discontinuation included adverse events, lack of efficacy, protocol violation, lost to follow-up, consent withdrawal and 'other' (Fig. 1b).

\section{Achievement of Sustained Remission}

After 48 weeks of open-label CZP treatment, $43.9 \%(323 / 736)$ patients had achieved sustained remission according to the study definition (Fig. 2a), including 42.8\% (174/407) r-axSpA and 45.3\% (149/329) nr-axSpA patients. Over the 48-week open-label treatment period, there was a gradual increase in the percentage of patients who achieved and then maintained ASDAS-ID (used in the definition of sustained remission) up to week 48 , with over a third $(35.6 \%)$ achieving and maintaining sustained remission from week 12 onwards, and approximately half $(52.0 \%)$ from week 24 onwards (Fig. 2b).

\section{Clinical and Quality of Life Outcomes}

Clinical improvements were observed as early as week 2 in the overall axSpA population, with $37.1 \%$ of patients reaching ASDAS $<2.1$ (including 25.9 and $11.2 \%$ with ASDAS-LD and ASDAS-ID, respectively; Fig. 3a). By week 4, half of all patients $(50.2 \%)$ had ASDAS $<2.1$.

At week $48,75.2 \%$ of all patients had ASDAS $<2.1$ (22.8\% with ASDAS-LD and 52.5\% with ASDAS-ID), with comparable responses 
Table 1 Baseline demographics and disease characteristics for patients enrolled in the C-OPTIMISE study

\begin{tabular}{|c|c|c|c|}
\hline & All axSpA $(n=736)$ & r-axSpA $(n=407)$ & $n r-a x S p A(n=329)$ \\
\hline \multicolumn{4}{|l|}{ Age, years } \\
\hline Mean (SD) & $32.9(7.0)$ & $33.7(6.8)$ & $32.1(7.1)$ \\
\hline Median (range) & $33.0(18-45)$ & $34.0(18-45)$ & $32.0(18-45)$ \\
\hline Male, $n(\%)$ & $514(69.8)$ & $319(78.4)$ & $195(59.3)$ \\
\hline BMI, $\mathrm{kg} / \mathrm{m}^{2}$, mean $(\mathrm{SD})$ & $25.7(4.9)$ & $25.6(4.7)$ & $25.8(5.1)$ \\
\hline \multicolumn{4}{|l|}{ Race, $n(\%)$} \\
\hline Caucasian & $681(92.5)$ & $375(92.1)$ & $306(93.0)$ \\
\hline Asian & $38(5.2)$ & $27(6.6)$ & $11(3.3)$ \\
\hline Other/mixed/missing & $17(2.3)$ & $5(1.2)$ & $12(3.6)$ \\
\hline \multicolumn{4}{|l|}{ Geographic region, $n(\%)$} \\
\hline North America & $33(4.5)$ & $13(3.2)$ & $20(6.1)$ \\
\hline Western Europe & $91(12.4)$ & $30(7.4)$ & $61(18.5)$ \\
\hline Eastern Europe & $537(73.0)$ & $320(78.6)$ & $217(66.0)$ \\
\hline Asia & $75(10.2)$ & $44(10.8)$ & $31(9.4)$ \\
\hline mNY positive, $n(\%)$ & $407(55.3)$ & $407(100.0)$ & 0 \\
\hline \multicolumn{4}{|l|}{ Symptom duration, years } \\
\hline Mean (SD) & $3.3(2.2)$ & $3.7(2.5)$ & $2.9(1.7)$ \\
\hline Median & 3.5 & 4.0 & 2.9 \\
\hline \multicolumn{4}{|l|}{ Time since diagnosis, years } \\
\hline Mean (SD) & $2.2(1.7)$ & $2.5(1.8)$ & $1.8(1.6)$ \\
\hline Median & 1.6 & 2.3 & 1.1 \\
\hline HLA-B27 positive, $n(\%)$ & $617(83.8)$ & $363(89.2)$ & $254(77.2)$ \\
\hline $\mathrm{CRP}>\mathrm{ULN}, n(\%)$ & $344(46.7)$ & $210(51.6)$ & $134(40.7)$ \\
\hline Prior TNFi therapy, $n(\%)$ & $32(4.3)$ & $20(4.9)$ & $12(3.6)$ \\
\hline History of enthesitis (heel), $n$ (\%) & $184(25.0)$ & $102(25.1)$ & $82(24.9)$ \\
\hline MASES > $0, n(\%)$ & $447(60.7)$ & $241(59.2)$ & $206(62.6)$ \\
\hline Peripheral arthritis, ${ }^{\mathrm{a}} n(\%)$ & $4(0.5)$ & $2(0.5)$ & $2(0.6)$ \\
\hline \multicolumn{4}{|l|}{ History of EMMs, $n(\%)$} \\
\hline Uveitis & $111(15.1)$ & $63(15.5)$ & $48(14.6)$ \\
\hline Inflammatory bowel disease & $17(2.3)$ & $9(2.2)$ & $8(2.4)$ \\
\hline Psoriasis & $45(6.1)$ & $24(5.9)$ & $21(6.4)$ \\
\hline \multicolumn{4}{|l|}{ Disease characteristics, mean (SD) } \\
\hline ASDAS & $3.7(0.8)$ & $3.9(0.8)$ & $3.6(0.8)$ \\
\hline
\end{tabular}


Table 1 continued

\begin{tabular}{llll}
\hline & All axSpA $(\boldsymbol{n}=\mathbf{7 3 6})$ & r-axSpA $(\boldsymbol{n}=\mathbf{4 0 7})$ & nr-axSpA $(\boldsymbol{n}=\mathbf{3 2 9})$ \\
\hline BASDAI & $6.7(1.4)$ & $6.7(1.4)$ & $6.7(1.4)$ \\
BASFI & $5.3(2.1)$ & $5.4(2.0)$ & $5.2(2.1)$ \\
BASMI & $3.1(1.5)$ & $3.5(1.6)$ & $2.6(1.3)$ \\
Tender joint count & $2.6(5.0)$ & $1.9(3.8)$ & $3.4(6.0)$ \\
Swollen joint count ${ }^{\mathrm{b}}$ & $0.7(2.1)$ & $0.5(1.4)$ & $1.1(2.7)$ \\
MASES, mean (SD) & $2.5(3.0)$ & $2.3(2.8)$ & $2.7(3.1)$ \\
Imaging (MRI), mean (SD) & & & $7.9(10.9)$ \\
SIJ SPARCC & $8.0(11.4)$ & $8.2(11.8)$ & $1.4(2.9)$ \\
ASspiMRI-a & $3.1(5.2)$ & $4.6(6.1)$ & \\
Concomitant medication, ${ }^{c} n(\%)$ & & & $69(21.0)$ \\
NSAIDs & $618(84.0)$ & $352(86.5)$ & \\
DMARDs & $166(22.6)$ & $97(23.8)$ & \\
\hline
\end{tabular}

Induction period baseline characteristics are reported

ASDAS Ankylosing Spondylitis Disease Activity Score, ASspiMRI-a Ankylosing Spondylitis spine MRI score for activity, BASDAI Bath Ankylosing Spondylitis Disease Activity Index, BASFI Bath Ankylosing Spondylitis Functional Index, $B A S M I$ Bath Ankylosing Spondylitis Metrology Index, BMI body mass index, CRP C-reactive protein, CZP certolizumab pegol, DMARD disease-modifying anti-rheumatic drug, EMM extra-musculoskeletal manifestation, HLA-B27 human leukocyte antigen B27, MASES Maastricht Ankylosing Spondylitis Enthesitis Score, $m N Y$ modified New York, MRI magnetic resonance imaging, $N S A I D$ non-steroidal anti-inflammatory drug, $Q 2 W$ every 2 weeks, $Q 4 W$ every 4 weeks, $S D$ standard deviation, SIJ SPARCC sacroiliac joint Spondyloarthritis Research Consortium of Canada, TNF tumor necrosis factor, $U L N$ upper limit of normal

${ }^{a}$ Reported as previous history or ongoing at baseline

b 44 joints

${ }^{c}$ Any intake during induction period (weeks 0-48).

amongst $\mathrm{r}$-axSpA and nr-axSpA patients (74.2 and $76.5 \%$, respectively; Table 2 ). This is compared to just $1.5 \%$ who had ASDAS $<2.1$ at study baseline. The percentage of patients reaching ASAS PR at week 48 (57.3\%) was similar to the percentage achieving ASDAS-ID (52.5\%). Similar trends were observed in ASAS20 and ASAS40 response rates, with 73.1 and $56.4 \%$ of patients achieving an ASAS20 and ASAS40 response, respectively, by week 12 , and 79.6 and $72.0 \%$ by week 48 (Fig. $3 \mathrm{~b}$ ).

Other outcome measures also demonstrated improvements at week 48, including those assessing disease activity (ASDAS and BASDAI),
Fig. 2 a Proportion of patients achieving sustained remission following 48 weeks' open-label CZP. b Kinetics of ASDAS-ID and ASDAS $<2.1$ achievement to week 48 in the 323 patients who achieved sustained remission. Non-responder imputation. ASDAS-ID Ankylosing Spondylitis Disease Activity Score inactive disease, ax $S p A$ axial spondyloarthritis, $r$-ax $S p A$ radiographic axial spondyloarthritis, $n$ r-ax $S p A$ non-radiographic spondyloarthritis

physical function (BASFI), mobility (BASMI) and quality of life (SF-36, ASQoL). All responses were comparable between $\mathrm{r}$-axSpA and nraxSpA subpopulations (Table 2). 
A

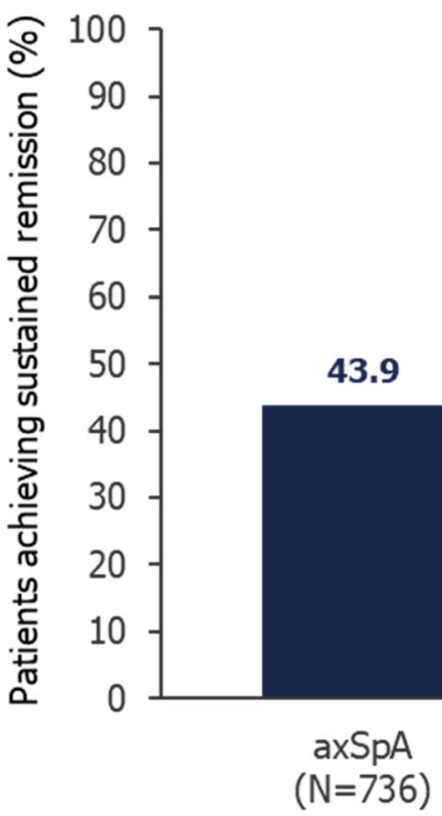

B

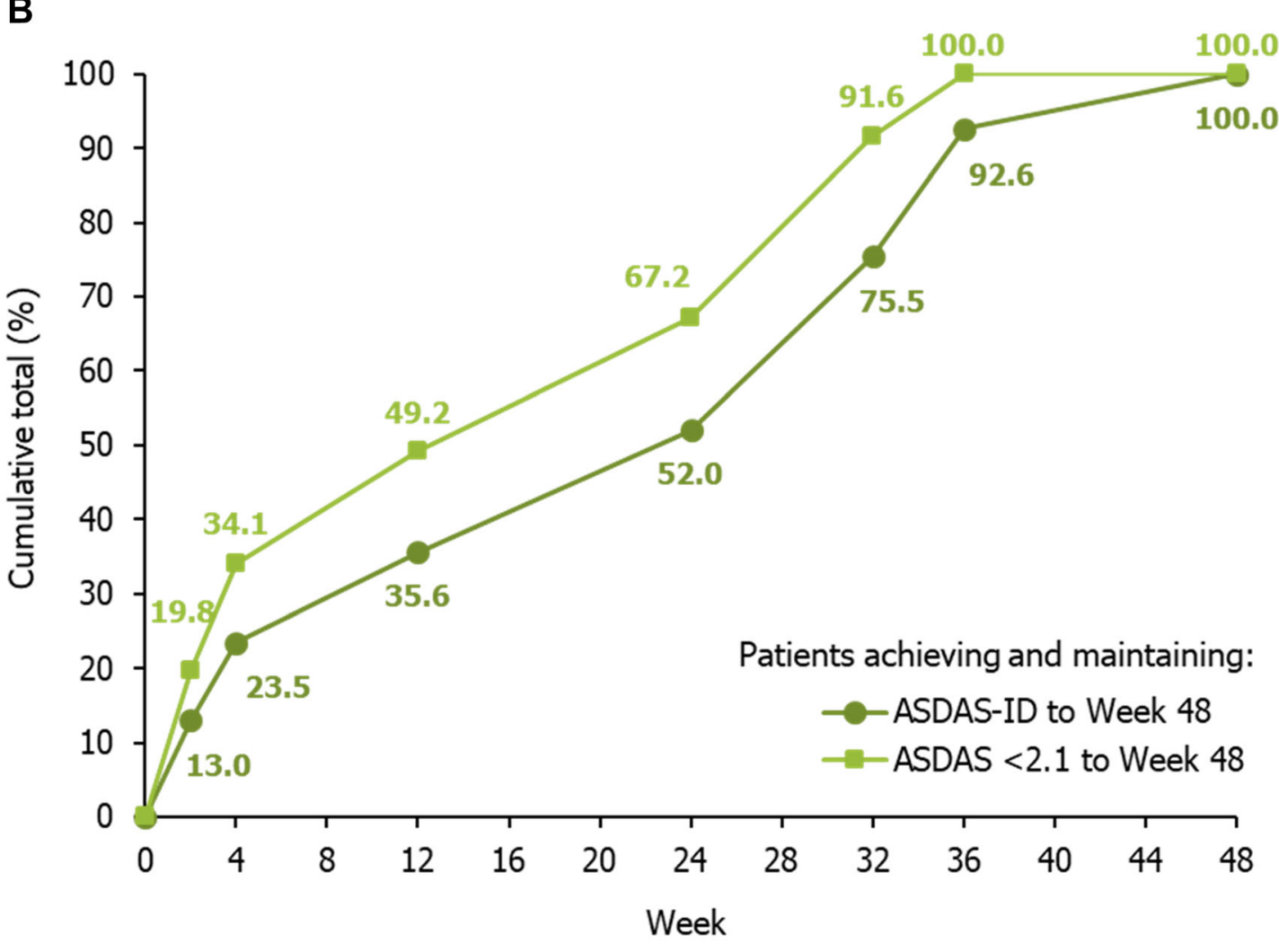




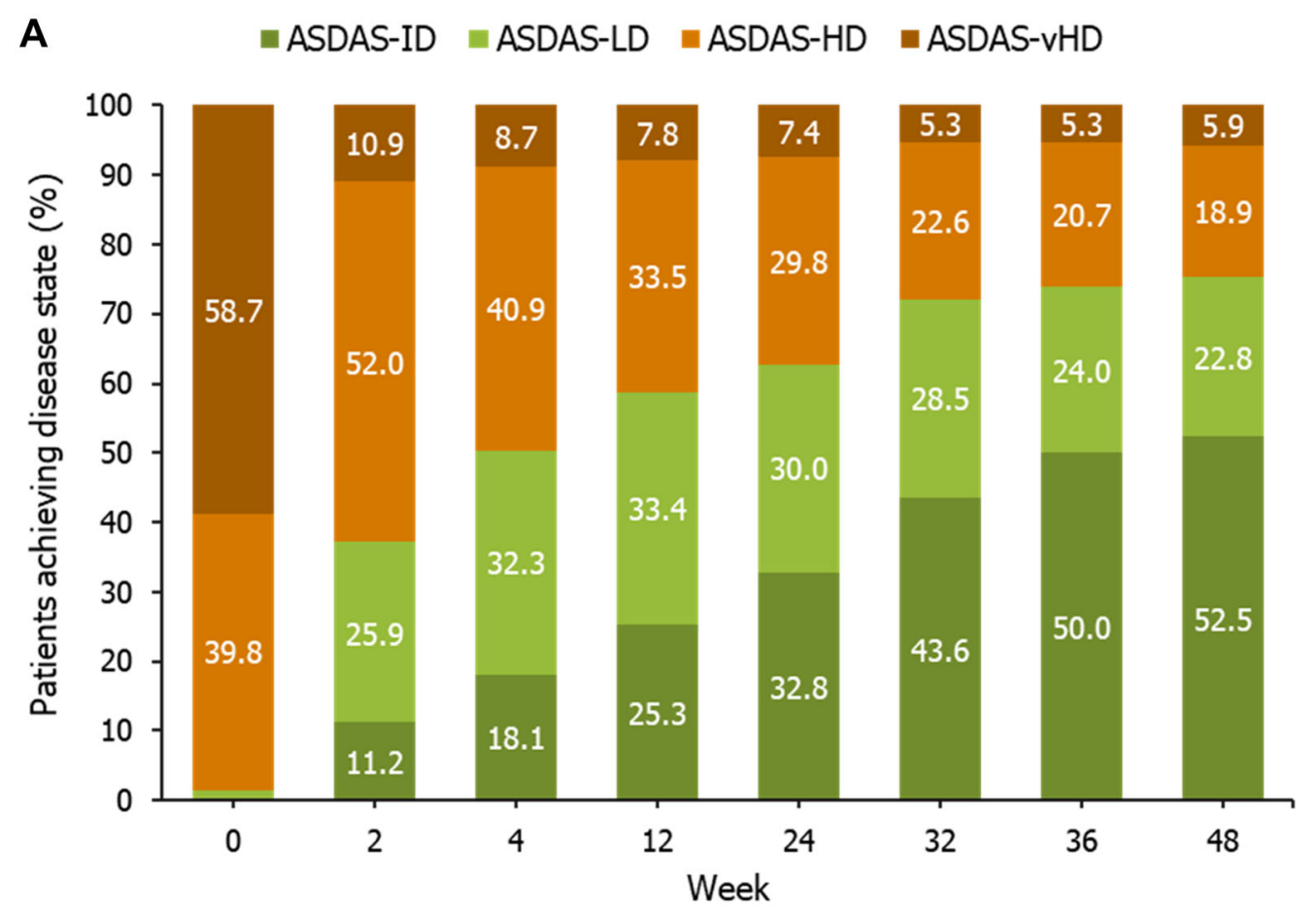

B

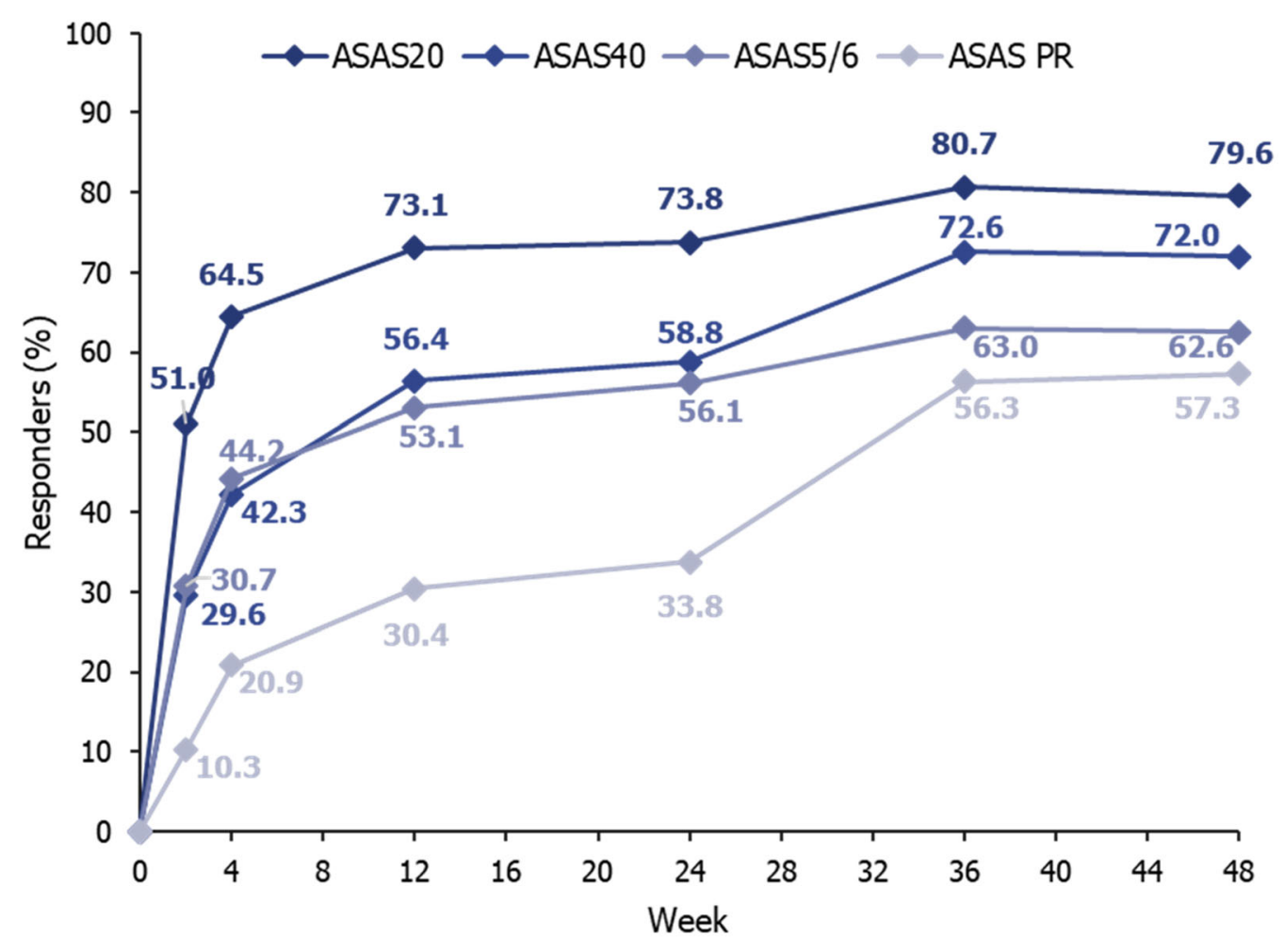


4Fig. 3 a ASDAS disease states and b ASAS responses during the 48-week induction period for the overall axSpA population $(N=736)$. ASDAS disease states: last observation carried forward; ASAS response: non-responder imputation, ASD $A S-I D / L D / H D / v H D$ Ankylosing Spondylitis Disease Activity Score inactive disease/low disease/high disease/very high disease, $A S A S$ Assessment of Spondyloarthritis international Society, axSpA axial spondyloarthritis

\section{MRI Outcomes}

Improvements were also reported for MRI outcomes assessing active inflammation in the SIJ and spine at week 48 across both axSpA subpopulations (Table 2). At baseline, mean SIJ SPARCC scores were comparable in patients with r-axSpA and nr-axSpA (8.2 and 7.9, respectively), and demonstrated similar reductions over the 48 weeks to 1.4 and 1.5 , respectively. ASspiMRI-a scores were higher at baseline in patients with $\mathrm{r}$-axSpA compared to nr-axSpA (4.6 and 1.4, respectively), but following 48 weeks' treatment had reduced substantially in both groups to 1.2 and 0.5 , respectively.

\section{Peripheral and Extra-Musculoskeletal Manifestations}

Despite higher baseline tender and swollen joint counts in patients with nr-axSpA (3.4 and 1.1 , respectively) compared with $\mathrm{r}$-axSpA (1.9 and 0.5 , respectively), at week 48 mean scores had improved in both subpopulations (Table 2). Improvements in enthesitis (MASES) were also reported at week 48 across all subpopulations (Table 2). In patients who had enthesitis at baseline, by week $48,72.6 \%(291 / 401)$ of all patients had achieved full enthesitis resolution (including 75.1\% [160/213] r-axSpA patients and $69.7 \%$ [131/188] nr-axSpA patients).

At baseline, 15.1\% (111/736) patients had a history of anterior acute uveitis (11 patients had uveitis at screening). During the 48-week induction period, $7.2 \%(8 / 111)$ of these patients experienced a total of ten uveitis flares. In the total population, including patients without any history of uveitis, $1.4 \%$ (10/736) patients experienced 13 uveitis flares.

At baseline, 17 of $736(2.3 \%)$ patients had a history of inflammatory bowel disease (nine with r-axSpA and eight with nr-axSpA). Of these 17 patients, $3(17.6 \%)$ had an exacerbation of their inflammatory bowel disease during the treatment period, all of whom had nr-axSpA. There were four de novo cases of inflammatory bowel disease, all in patients with r-axSpA.

\section{Safety}

During the 48-week open-label induction period, TEAEs were reported for $67.9 \%$ of axSpA patients $(67.3 \%$ of patients with $\mathrm{r}$-axSpA and $68.7 \%$ of patients with nr-axSpA; Table 3). Serious TEAEs were reported for $6.0 \%$ of axSpA patients $(\mathrm{ER}=6.74 / 100 \mathrm{PY})$. The rates of serious TEAEs were similar for patients with $\mathrm{r}$-axSpA $(6.1 \%, \mathrm{ER}=7.02 / 100 \mathrm{PY})$ and $\mathrm{nr}-\mathrm{axSpA}$ patients $(5.8 \%, \mathrm{ER}=6.40 / 100 \mathrm{PY})$.

There were two reported cases of opportunistic infection, both serious and in patients with r-axSpA; this included one case of pulmonary tuberculosis (resolving at the time of preliminary drop-out) and one of tuberculous pleurisy (resolved). Patients were tested for the signs and symptoms of latent or active TB infection before CZP treatment; both of these cases had an onset after the start of treatment, were considered to be treatment-related, and occurred in patients based in Romania. There were 13 reported cases of oral herpes, and ten of these were in patients with $\mathrm{r}-\mathrm{axSpA}(2.5 \%$ of r-axSpA patients); five of the 13 cases were considered to be related to the study drug. A single case of demyelinating disorder (optic neuritis) was reported in a patient with nraxSpA and judged to be related to the study drug by the investigator. There were no reported cases of oral candidiasis, malignancy, serious cardiovascular or bleeding events. No deaths were reported.

\section{DISCUSSION}

The induction period of the C-OPTIMISE trial evaluated the achievement of sustained 


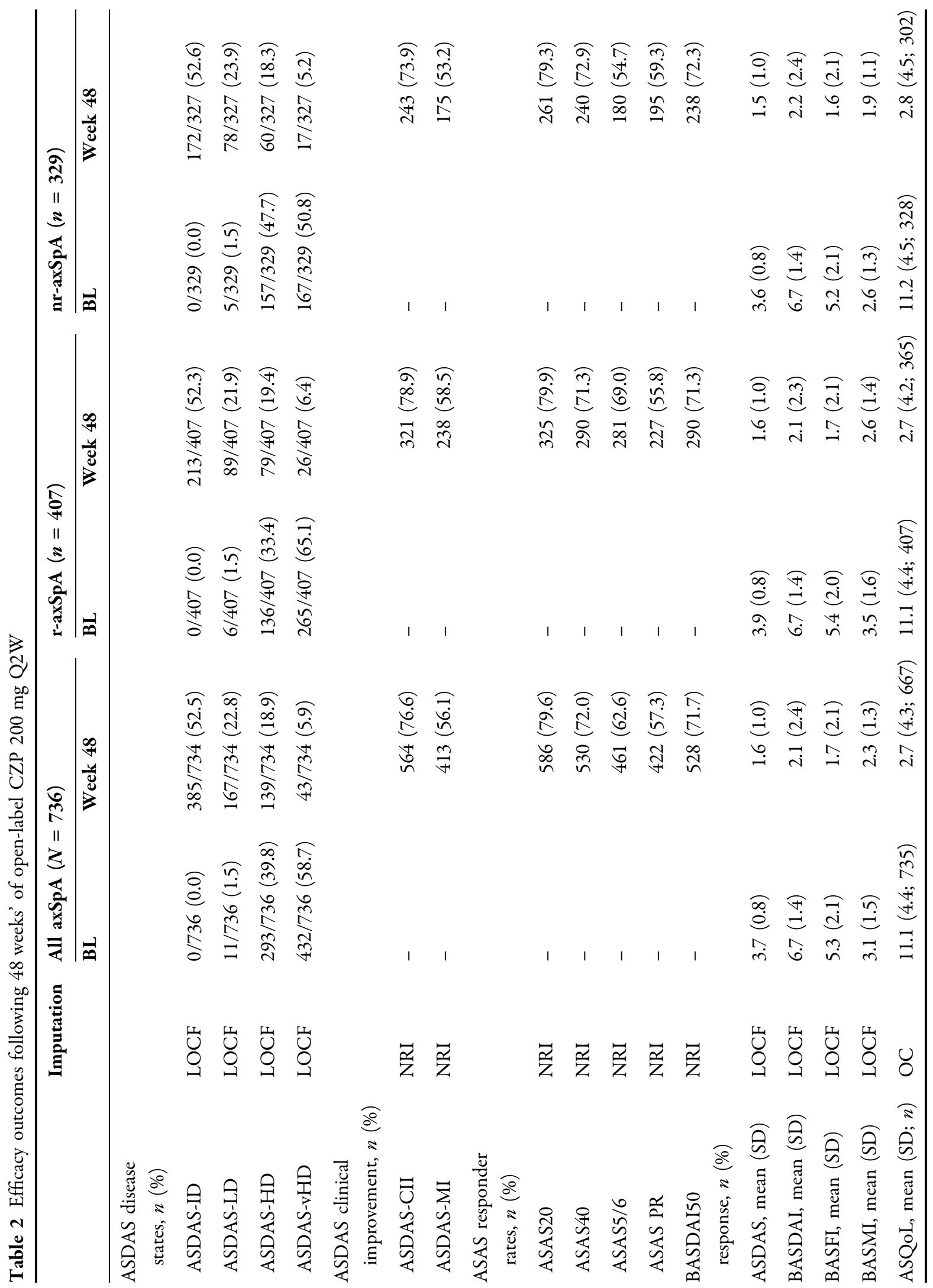




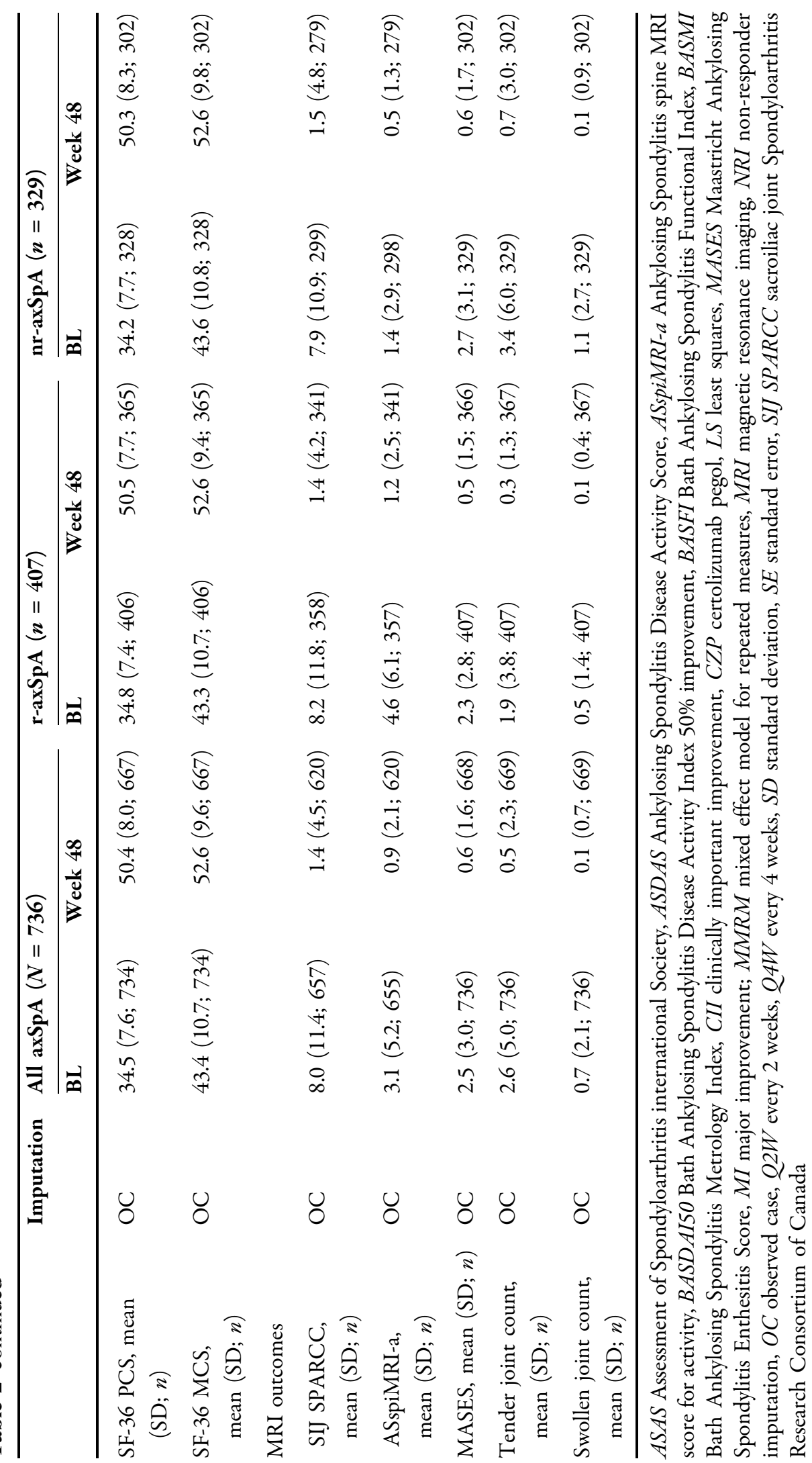


Table 3 Safety outcomes for r-axSpA and nr-axSpA subpopulations at the end of the induction period (week 48)

\begin{tabular}{|c|c|c|c|}
\hline$n$ (\%), unless otherwise specified & All axSpA $(n=736)$ & $\mathrm{r}-\operatorname{axSpA}(n=407)$ & nr-axSpA $(n=329)$ \\
\hline \multicolumn{4}{|l|}{ CZP exposure duration (days) } \\
\hline Mean (SD) & $317.1(64.0)$ & $315.4(66.6)$ & $319.3(60.7)$ \\
\hline Median (range) & $336.0(14-384)$ & $336.0(14-384)$ & $336.0(14-369)$ \\
\hline Patient-years at risk & 697.1 & 384.4 & 312.7 \\
\hline Any TEAE & $500(67.9)$ & $274(67.3)$ & $226(68.7)$ \\
\hline Event rate per $100 \mathrm{PY}$ & 225.0 & 211.0 & 242.1 \\
\hline Serious TEAEs & $44(6.0)$ & $25(6.1)$ & $19(5.8)$ \\
\hline Event rate per $100 \mathrm{PY}$ & 6.7 & 7.0 & 6.4 \\
\hline Discontinuation due to TEAEs & $31(4.2)$ & $18(4.4)$ & $13(4.0)$ \\
\hline Drug-related TEAEs & $194(26.4)$ & $105(25.8)$ & $89(27.1)$ \\
\hline \multicolumn{4}{|l|}{ TEAEs of interest } \\
\hline Opportunistic infections & $2(0.3)$ & $2(0.5)$ & 0 \\
\hline Pulmonary tuberculosis & $1(0.1)$ & $1(0.2)$ & 0 \\
\hline Tuberculous pleurisy & $1(0.1)$ & $1(0.2)$ & 0 \\
\hline Oral candidiasis & 0 & 0 & 0 \\
\hline Malignant or unspecified tumors & 0 & 0 & 0 \\
\hline Serious cardiovascular events & 0 & 0 & 0 \\
\hline Serious hematopoietic cytopenia & 0 & 0 & 0 \\
\hline Serious bleeding events & 0 & 0 & 0 \\
\hline Hepatic events & $46(6.3)$ & $26(6.4)$ & $20(6.1)$ \\
\hline Liver function analyses & $32(4.3)$ & $19(4.7)$ & $13(4.0)$ \\
\hline Hypersensitivity and anaphylactic reactions & $3(0.4)$ & 0 & $3(0.9)$ \\
\hline Demyelinating disorders ${ }^{\mathrm{a}}$ & $1(0.1)$ & 0 & $1(0.3)$ \\
\hline Deaths & 0 & 0 & 0 \\
\hline
\end{tabular}

axSpA axial spondyloarthritis, $C Z P$ certolizumab pegol, $P Y$ patient-years, $Q 2 W$ every 2 weeks, $Q 4 W$ every 4 weeks, TEAE treatment-emergent adverse event

a The singular case of demyelinating disorder was optic neuritis, judged to be related to the study drug by the investigator. Safety events are reported for the safety set $(N=736)$ according to the Medical Dictionary for Regulatory Activities version 19.0

remission in patients with early axSpA, including both $\mathrm{r}$ - and nr-axSpA, during 48 weeks' open-label CZP treatment. The definition of remission in C-OPTIMISE was based on achievement of ASDAS-ID $(<1.3)$, a disease activity measure in axSpA that is considered in the ASAS/EULAR recommendations to reflect a state of clinical remission [30, 31]. The definition of 'sustained' remission also corresponds to that used in the ABILITY-3 study, by requiring 
patients to have ASDAS-ID at consecutive timepoints over at least 12 weeks, although the overall induction period in C-OPTIMISE was longer (48 vs. 28 weeks) [18]. Since there is no widely established definition for clinical remission in axSpA, definitions used in previous, mostly observational, studies have been heterogeneous [19].

Using the study definition for sustained remission, over $40 \%$ of patients had reached sustained remission by week 48. All of these patients were in sustained remission for at least 12 weeks, but $23.5 \%$ achieved and maintained ASDAS-ID from week 4 onwards, and $52.0 \%$ from week 24 onwards. This means that almost a quarter of patients were in a state of deep sustained remission for nearly a year (44 weeks), and approximately half were in sustained remission for 6 months.

The response to CZP was similar for r-axSpA and nr-axSpA patients, with 42.8 and $45.3 \%$, respectively, achieving sustained remission. Given that the burden of disease is similar amongst the two axSpA subpopulations [6], the finding that similar proportions of patients can achieve clinical remission after CZP treatment further supports the concept of axSpA as a single disease, encompassing both $\mathrm{r}$ - and nr-axSpA.

Across other measures, responses showed similar rapid and sustained improvements over the 48-week treatment period. Over half of all patients had reached ASAS PR, another measure of remission, by the end of the induction period, with a fifth of patients achieving ASAS PR at week 4 . Improvements in patient mobility and physical function were also observed, as assessed by the BASMI and BASFI, respectively. As the physical limitations of axSpA can impact on many areas of a patient's life, including employment, social relationships and mood, improvements in these outcomes are crucial to patients' quality of life [32, 33]. Indeed, there were also improvements in the ASQoL and SF36 quality of life measures. Finally, patients also demonstrated improvements in extra-musculoskeletal and peripheral manifestations of disease, including enthesitis, uveitis, inflammatory bowel disease and peripheral arthritis. For all measures, responses were similar across $r$-axSpA and nr-axSpA subpopulations, further validating the unified axSpA concept, and supporting results from a recent meta-analysis which suggested that the treatment effect is comparable in both subpopulations [6].

Structural progression of disease is a risk in axSpA, both in r-axSpA and nr-axSpA, and has an impact on the degree of disability experienced by patients [34]. Active inflammation is known to be a predictor of structural disease progression, and is reflected in MRI outcomes including ASspiMRI-a and SIJ SPARCC [35]. In C-OPTIMISE, substantial improvements were shown in ASspiMRI-a and SIJ SPARCC outcomes in both subpopulations after 48 weeks of CZP treatment.

The results from this study are also comparable with previous studies assessing the efficacy and tolerability of CZP in patients with axSpA $[14,21]$. RAPID-axSpA, a phase 3 randomized controlled trial (NCT01087762), investigated the effect of CZP on a broad axSpA population, and was double-blind and placebo-controlled to week 24, dose-blind to week 48 and open-label to week 204 [14]. The study investigated improvements in clinical and patient-reported outcomes in a controlled setting, providing a valuable comparison for the secondary outcomes of this open-label trial across the same time period [14]. After 48 weeks of treatment, approximately 70 and $60 \%$ of patients in RAPID-axSpA achieved ASAS20 and ASAS40, respectively, compared to 79.6 and $72.0 \%$ in this study [14]. It is possible that the increase in the percentages of patients achieving ASAS20/ 40 in C-OPTIMISE is attributable to the openlabel nature of this study period, as patients in RAPID-axSpA were blinded up to week 48 [14]. However, the increase may also be affected by the younger patient population in C-OPTIMISE (mean patient age 32.9 years vs. 39.5 years in RAPID-axSpA) or the shorter symptom duration in C-OPTIMISE (median 3.5 years vs. 7.7 years in RAPID-axSpA) [36].

Despite the overall lower ASAS40 response rates in RAPID-axSpA, it is important to note that similar percentages of patients with r-axSpA and nr-axSpA achieved ASAS40 (approximately 59 and $57 \%$, respectively), which was also observed in C-OPTIMISE (71.3 and $72.9 \%$, respectively) [14]. This indicates that 
r-axSpA and nr-axSpA patient populations achieve similar ASAS40 outcomes, regardless of open-label or blinded treatment, highlighting that TNFi treatment is equally effective in both patient groups.

Improvements in axSpA symptoms and quality of life for patients during the induction period of C-OPTIMISE were also comparable to those observed in the C-axSpAnd trial (NCT02552212), a double-blind, placebo-controlled trial which focused on patients with nraxSpA [21]. In C-axSpAnd, $47.2 \%$ of patients with nr-axSpA achieved ASDAS-MI (52-week data), compared to $53.2 \%$ of patients with nraxSpA in C-OPTIMISE at 48 weeks [21].

Safety data reported for the induction period of C-OPTIMISE were comparable to previous reports for CZP in axSpA and no new safety signals were identified $[14,21]$.

A potential limitation of the induction period of C-OPTIMISE is the fact that it was openlabel with no placebo comparator arm, which may introduce an element of bias to the observed improvements, particularly as many of the outcomes are patient-reported. Indeed, clinical responses during the induction period such as ASAS20/40 were higher than in previous double-blinded studies of CZP in axSpA, indicating that perception bias may have impacted the outcomes [14, 21]. However, it is also important to note that there were large improvements in objective measures such as MRI outcomes.

In summary, the induction period of C-OPTIMISE evaluated the achievement of sustained remission in patients across the axSpA spectrum in a controlled setting. Sustained remission was achieved in over $40 \%$ of patients during 48 weeks of open-label treatment with CZP, demonstrating the benefits of early treatment in patients with axSpA. Improvements in disease activity and other outcome measures were comparable across $\mathrm{r}$-axSpA and nr-axSpA patient groups, supporting the findings of previous studies in this area, with no new safety signals identified.

\section{ACKNOWLEDGEMENTS}

The authors thank the patients, the investigators, and their teams who took part in this study. The authors also acknowledge Christian Stach, UCB Pharma, for contributions to study design, Simone E. Auteri, MSc EMS PhD, UCB Pharma, Brussels, Belgium, for publication coordination.

Funding. This article was based on the original study AS0005/C-OPTIMISE (NCT02505542) sponsored by UCB Pharma. This study and the journal's Rapid Service Fee was funded by UCB Pharma.

Medical Writing Assistance. Support for third-party writing assistance for this article, provided by Olivia Wakeman, BSc, and Jessica Patel, PhD, Costello Medical, UK, was funded by UCB Pharma in accordance with Good Publication Practice guidelines (https://www.ismpp. org/gpp3).

Authorship. All named authors meet the International Committee of Medical Journal Editors (ICMJE) criteria for authorship for this article, take responsibility for the integrity of the work as a whole, and have given their approval for this version to be published.

Authorship Contributions. Substantial contributions to study conception and design: RL, DvdH, MD, XB, FVdB, KG, LB, BH, and LSG; contributions to analysis and interpretation of the data: RL, DvdH, MD, XB, FVdB, KG, NdP, LB, BH, KT and LSG; drafting the article or revising it critically for important intellectual content: RL, DvdH, MD, XB, FVdB, KG, NdP, LB, $\mathrm{BH}, \mathrm{KT}$ and LSG; final approval of the version of the article to be published: RL, DvdH, MD, XB, FVdB, KG, NdP, LB, BH, KT, and LSG.

Disclosures. Robert Landewé: Consulting fees, research grants and/or speaker's bureau from Abbott, Ablynx, Amgen, AstraZeneca, Bristol-Myers Squibb, Centocor, Galapagos, GlaxoSmithKline, Merck, Novartis, Pfizer, Roche, Schering-Plough, UCB Pharma and Wyeth. Désirée van der Heijde: Consulting fees 
from AbbVie, Amgen, Astellas, AstraZeneca, Bristol-Myers Squibb, Boehringer Ingelheim, Celgene, Cyxone, Daiichi, Eli Lilly, Galapagos, Gilead, Janssen, Merck, Novartis, Pfizer, Regeneron, Roche, Sanofi, Takeda and UCB Pharma; director of Imaging Rheumatology BV. Maxime Dougados: Consultancy/speaker fees/research grants from AbbVie, Eli Lilly, Novartis, Merck, Pfizer and UCB Pharma. Xenofon Baraliakos: Consultancy/speaker fees/research grants from AbbVie, Bristol-Myers Squibb, Celgene, Chugai, Janssen, MSD, Novartis, Pfizer and UCB Pharma; grant/research support from AbbVie, BristolMyers Squibb and Celgene. Filip Van den Bosch: Consultancy fees from AbbVie, Bristol MyersSquibb, Celgene, Janssen, Merck, Novartis, Pfizer and UCB Pharma; speakers bureau fees from AbbVie, Bristol Myers-Squibb, Celgene, Janssen, Merck, Novartis, Pfizer and UCB Pharma. Karl Gaffney: Consulting fees/research grants from AbbVie, Celgene, MSD, Novartis, Pfizer and UCB Pharma. Natasha de Peyrecave, Lars Bauer, Bengt Hoepken: Employees of UCB Pharma. Karen Thomas: Independent statistician contracted to UCB Pharma. Lianne S. Gensler: Grant/research support from AbbVie, Amgen, Novartis and UCB Pharma; consulting fees from Galapagos, Eli Lilly and Janssen.

Compliance with Ethics Guidelines. The C-OPTIMISE study was approved by institutional review boards and independent ethics committees at participating sites (Supplementary Material) and was conducted in accordance with local regulations and the International Conference on Harmonization Good Clinical Practice requirements, based on the Declaration of Helsinki. All patients provided informed consent to participate.

Data Availability. Underlying data from this manuscript may be requested by qualified researchers 6 months after product approval in the US and/or Europe, or global development is discontinued, and 18 months after trial completion. Investigators may request access to anonymized individual patient-level data and redacted trial documents which may include: analysis-ready datasets, study protocol, annotated case report form, statistical analysis plan, dataset specifications, and clinical study report. Prior to use of the data, proposals need to be approved by an independent review panel at https://www.Vivli.org and a signed data sharing agreement will need to be executed. All documents are available in English only, for a prespecified time, typically 12 months, on a password protected portal.

Open Access. This article is licensed under a Creative Commons Attribution-NonCommercial 4.0 International License, which permits any non-commercial use, sharing, adaptation, distribution and reproduction in any medium or format, as long as you give appropriate credit to the original author(s) and the source, provide a link to the Creative Commons licence, and indicate if changes were made. The images or other third party material in this article are included in the article's Creative Commons licence, unless indicated otherwise in a credit line to the material. If material is not included in the article's Creative Commons licence and your intended use is not permitted by statutory regulation or exceeds the permitted use, you will need to obtain permission directly from the copyright holder. To view a copy of this licence, visit http://creativecommons.org/licenses/by$\mathrm{nc} / 4.0 /$.

\section{REFERENCES}

1. Poddubnyy D. Axial spondyloarthritis: is there a treatment of choice? Ther Adv Musculoskelet Dis. 2013;5:45-54.

2. Ghosh N, Ruderman EM. Nonradiographic axial spondyloarthritis: clinical and therapeutic relevance. Arthritis Res Ther. 2017;19:286.

3. Deodhar A, Strand V, Kay J, et al. The term 'nonradiographic axial spondyloarthritis' is much more important to classify than to diagnose patients with axial spondyloarthritis. Ann Rheum Dis. 2016;75: 791-4.

4. Khan MA, van der Linden S. Axial spondyloarthritis: a better name for an old disease: a step toward uniform reporting. ACR Open Rheumatol. 2019;1: 336-9. 
5. Ciurea A, Scherer A, Exer P, et al. Tumor necrosis factor alpha inhibition in radiographic and nonradiographic axial spondyloarthritis: results from a large observational cohort. Arthritis Rheum. 2013;65:3096-106.

6. López-Medina C, Ramiro S, van der Heijde D, et al. Characteristics and burden of disease in patients with radiographic and non-radiographic axial Spondyloarthritis: a comparison by systematic literature review and meta-analysis. RMD Open. 2019;5:e001108.

7. Feldtkeller E, Khan MA, van der Heijde D, et al. Age at disease onset and diagnosis delay in HLA-B27 negative vs. positive patients with ankylosing spondylitis. Rheumatol Int. 2003;23:61-6.

8. Redeker I, Callhoff J, Hoffmann F, et al. Determinants of diagnostic delay in axial spondyloarthritis: an analysis based on linked claims and patient-reported survey data. Rheumatology. 2019;58: 1634-8.

9. Sørensen J, Hetland ML, All departments of rheumatology in Denmark. Diagnostic delay in patients with rheumatoid arthritis, psoriatic arthritis and ankylosing spondylitis: results from the Danish nationwide DANBIO registry. Ann Rheum Dis. 2015;74:e12.

10. Danve A, Deodhar A. Axial spondyloarthritis in the USA: diagnostic challenges and missed opportunities. Clin Rheumatol. 2019;38:625-34.

11. Masson Behar V, Dougados M, Etcheto A, et al. Diagnostic delay in axial spondyloarthritis: a crosssectional study of 432 patients. Jt Bone Spine. 2017;84:467-71.

12. Sykes MP, Doll H, Sengupta R, et al. Delay to diagnosis in axial spondyloarthritis: are we improving in the UK? Rheumatology. 2015;54:2283-4.

13. Ward MM, Deodhar A, Gensler LS, et al. 2019 Update of the American College of Rheumatology/ Spondylitis Association of America/spondyloarthritis research and treatment network recommendations for the treatment of ankylosing spondylitis and nonradiographic axial spondyloarthritis. Arthritis Rheumatol. 2019;71:1599-613.

14. van der Heijde D, Dougados M, Landewe R, et al. Sustained efficacy, safety and patient-reported outcomes of certolizumab pegol in axial spondyloarthritis: 4-year outcomes from RAPID-axSpA. Rheumatology. 2017;56:1498-509.

15. Edwards CJ, Fautrel B, Schulze-Koops H, et al. Dosing down with biologic therapies: a systematic review and clinicians' perspective. Rheumatology. 2017;56:1847-56.
16. Hindryckx P, Zou GY, Feagan BG, et al. Biologic drugs for induction and maintenance of remission in Crohn's disease: a network meta-analysis. Cochrane Database Syst Rev 2017;2017.

17. Emery P, Hammoudeh M, FitzGerald O, et al. Sustained remission with etanercept tapering in early rheumatoid arthritis. N Engl J Med. 2014;371: 1781-92.

18. Landewé R, Sieper J, Mease P, et al. Efficacy and safety of continuing versus withdrawing adalimumab therapy in maintaining remission in patients with non-radiographic axial spondyloarthritis (ABILITY-3): a multicentre, randomised, double-blind study. Lancet. 2018;392:134-44.

19. Navarro-Compan V, Plasencia-Rodriguez C, de Miguel E, et al. Anti-TNF discontinuation and tapering strategies in patients with axial spondyloarthritis: a systematic literature review. Rheumatology. 2016;55:1188-94.

20. Marin J, Acosta Felquer ML, Soriano ER. Spotlight on certolizumab pegol in the treatment of axial spondyloarthritis: efficacy, safety and place in therapy. Open Access Rheumatol. 2018;10:33-41.

21. Deodhar A, Gensler LS, Kay J, et al. A fifty-twoweek, randomized, placebo-controlled trial of certolizumab pegol in nonradiographic axial spondyloarthritis. Arthritis Rheumatol. 2019;71:1101-11.

22. Landewé $\mathrm{R}$, van der Heijde $\mathrm{D}$, Dougados $\mathrm{M}$, et al. Maintenance of clinical remission in early axial spondyloarthritis following certolizumab pegol dose reduction. Ann Rheum Dis. 2020. https://doi. org/10.1136/annrheumdis-2019-216839.

23. Machado P, Landewé R, Lie E, et al. Ankylosing Spondylitis Disease Activity Score (ASDAS): defining cut-off values for disease activity states and improvement scores. Ann Rheum Dis. 2011;70: 47-53.

24. Machado PM, Landewé R, van der Heijde D. Ankylosing Spondylitis Disease Activity Score (ASDAS): 2018 update of the nomenclature for disease activity states. Ann Rheum Dis. 2018;77:1539-40.

25. Rudwaleit M, van der Heijde D, Landewé R, et al. The Assessment of SpondyloArthritis International Society classification criteria for peripheral spondyloarthritis and for spondyloarthritis in general. Ann Rheum Dis. 2011;70:25-31.

26. van der Linden S, Valkenburg HA, Cats A. Evaluation of diagnostic criteria for ankylosing spondylitis. A proposal for modification of the New York criteria. Arthritis Rheum. 1984;27:361-8. 
27. Doward LC, Spoorenberg A, Cook SA, et al. Development of the ASQoL: a quality of life instrument specific to ankylosing spondylitis. Ann Rheum Dis. 2003;62:20-6.

28. Ware JE Jr, Sherbourne CD. The MOS 36-item shortform health survey (SF-36). I. Conceptual framework and item selection. Med Care. 1992;30: 473-83.

29. Maksymowych WP, Inman RD, Salonen D, et al. Spondyloarthritis research Consortium of Canada magnetic resonance imaging index for assessment of sacroiliac joint inflammation in ankylosing spondylitis. Arthritis Care Res. 2005;53:703-9.

30. Marzo-Ortega H, Gaffney K, Gaffney K. Defining the target: clinical aims in axial spondyloarthritis. Rheumatology. 2018;57:vi18-vi22.

31. van der Heijde D, Ramiro S, Landewé R, et al. 2016 update of the ASAS-EULAR management recommendations for axial spondyloarthritis. Ann Rheum Dis. 2017;76:978.

32. Osterhaus JT, Purcaru O. Discriminant validity, responsiveness and reliability of the arthritis- specific work productivity survey assessing workplace and household productivity within and outside the home in patients with axial spondyloarthritis, including nonradiographic axial spondyloarthritis and ankylosing spondylitis. Arthritis Res Ther. 2014;16:R164.

33. Strand V, Singh JA. Patient burden of axial spondyloarthritis. J Clin Rheumatol. 2017;23: 383-91.

34. Aouad K, Ziade N, Baraliakos X. Structural progression in axial spondyloarthritis. Jt Bone Spine. 2019;87:131-6.

35. Ramiro S, van der Heijde D, Sepriano A, et al. Spinal radiographic progression in early axial spondyloarthritis: five-year results from the DESIR cohort. Arthritis Care Res. 2019;71:1678-84.

36. Landewé R, Braun J, Deodhar A, et al. Efficacy of certolizumab pegol on signs and symptoms of axial spondyloarthritis including ankylosing spondylitis: 24-week results of a double-blind randomised placebo-controlled phase 3 study. Ann Rheum Dis. 2014;73:39-47. 